\title{
A Microplate Assay for Sialidase Activity Using Plant Lectin Binding to $\mathrm{N}$-Acetyllactosamine
}

\author{
Satoshi ONODERA \\ Department of Clinical Chemistry, Showa College of Pharmaceutical Sciences, Machida, Tokyo 194, Japan.
}

Received June 10, 1993

\begin{abstract}
This paper presents a sensitive assay for sialidase activity based on the specific binding of lecting to $\mathrm{N}$-acetyllactosamine. The substrate used for sialidase assay is fetuin $(30-100 \mathrm{ng} / 50 \mu \mathrm{l})$ with sialilated oligosaccharides, which was then coated on a 96-well microtiterplate. After removing sialic acids from the terminal positions of the glycoconjugate glycans by sialidase, it was subjected to biotin-labeled lectin (Ricinus communis agglutinin 120), which binds specifically to $N$-acetyllactosamine. This was followed by the addition of a peroxidase conjugated avidin-biotin complex. The amount of bound peroxidase was determined by a colorimetric assay. The sensitivity was enhanced 1000- to 10000-fold compared to the colorimetric assay using a synthetic substrate such as 2-O-(p-nitrophenyl)- $N$-acetyl- $\alpha$-D-neuraminic acid (PNPN). In the established method, only very small amounts of substrate and sialidase were required; therefore, it can be applied to the quantitative assay of some sialidases from Vibrio cholerae, streptococcus, the influenza virus and rat liver.
\end{abstract}

Keywords sialidase; lectin; avidin-biotin; neuraminidase

Sialidase (EC 3.2.1.18) is one of the important exoglycosidases, which are involved in the metabolism of glycoproteins and glycolipid sugar chains. Sialic acid at the terminal, nonreducing end of many oligosaccharide chains of glycoconjugates have significant biological functions such as the clearance of circulating sialoglycoproteins, acting as a receptor for various peptide hormones and viruses, and also as a regulator of cell-cell interactions. ${ }^{1,2)}$ Quantitative variations in binding sialic acid to an oligosaccharide may be regulated by the balance between sialidase and sialyltransferase activity in tissues. In connection with this function, there has been recent interest in these enzymes in terms of infection by bacteria and the influenza virus, cell growth and differentiation, and tumor cells.

Up to this time, the main assay of sialidase activity has been done using the following methods: 1) colorimetric assay of sialic acids released from sialyl compounds such as glycoproteins and gangliosides ${ }^{3,4)}$;2) measurement of the chromogen released from a synthetic chromogenic substrate $^{5)}$; 3) measurement of the fluorescence of methylumbelliferone released from a synthetic fluorescent substrate ${ }^{6)}$; 4) radioisotopic assay using tritium-labeled sialyl oligosaccharide substrates ${ }^{7)}$; and 5) peroxidase or lectin amplified assay. ${ }^{8-11)}$ The above assays have been routinely utilized. However, methods 1) and 2) cannot measure very low sialidase activity and often do not give reliable results with crude enzyme preparations. Systems 3-5 are extremely sensitive. However, in most areas of study it is generally inconvenient to provide a special place for using a radioisotope, they involve time-consuming systems which utilize chromatographic methods prior to measurement, and the cost of using these is prohibitive.

The procedure using a microplate, in this paper, is based on the specific binding of lectin to desialilated $N$-acetyllactosamine, and was effective for measuring many samples, such as multiple samples from body fluids and tissues. It can also be used to monitor sialidase activity during chromatography for sialidase purification.

\section{MATERIALS AND METHODS}

Materials Bovine fetuin was purchased from Canadian Bioclinical, Ltd., Scarborough, Canada. Asialofetuin (type I from fetal calf serum) and taurodeoxycholic acid (sodium salt) were purchased from Sigma Chemical Co., St. Louis, U.S.A. Sialidase from Streptococcus S.P., $\beta$ galactosidase (Jack bean), Biotin-RCA ${ }_{120}$ (Ricinus communis agglutinin 120$)$ and PNPN [2-O-( $p$-nitrophenyl)$N$-acetyl- $\alpha$-D-neuraminic acid ( $\mathrm{Na}$ salt)] were obtained from Seikagaku Kogyo Co., Ltd., Tokyo, Japan. Sialidase from Vibrio cholerae was supplied by Boehringer Mannheim, Germany. The vectastain ABC kit (Avidin DH and biotinylated horseradish peroxidase $\mathrm{H}$ ) was obtained from Vector Laboratories, Inc., Burlingame, U.S.A. 4-Methylumbelliferyl- $N$-acetyl- $\alpha$-D-neuraminic acid ammonium salt was purchased from Nacalai Tesque, Inc., Kyoto, Japan. Bovine albumin (Chon fraction V powder) was from Amour Pharmaceutical Co., Tokyo, Japan. Gelatin was supplied by Funakoshi Co., Ltd., Tokyo, Japan. The 96-well polystyrene microtiter plate (Sumilon) was purchased from Sumitomo Bakelite, Ltd., Tokyo, Japan. $o$-Phenylendiamine was obtained from Tokyo Kasei Kogyo Co., Ltd., Tokyo, Japan. The sialic acid test reagents were purchased from Kyokuto Pharmaceutical Industrial Co., Ltd., Tokyo, Japan. The Bio-Rad Protein Assay Dye Reagent Concentrate was obtained from Bio-Rad Laboratories, Richmond, U.S.A. D(+)-Mannose, lactose monohydrate, galactose, dextrose anhydrous (glucose), $\mathrm{N}$-acetyl-D( +)-glucosamine, polyoxyethene(20) sorbitan monolaurate (Tween 20) and polyoxyethylene(10) octylphenyl ether (Triton X-100) were purchased from Wako Pure Chemical Industries, Ltd., Osaka, Japan. $N$-Acetyl-D-galactosamine was obtained from E $\cdot Y$ LABS, Inc, San Mateo, U.S.A. The purified influenza virus (A/Aichi/2/68, H3N3) was a generous gift from Prof. Y. Suzuki (University of Shizuoka, School of Pharmaceuti- 
cal Science, Japan). The rat liver sialidase was prepared as described previously. ${ }^{12)}$

Coating of 96-Well Microtiter Plate with Fetuin The wells were coated with $50 \mu$ lof the $0.1 \mathrm{M}$ carbonate buffer solution, $\mathrm{pH} 9.7$, containing $30-100 \mathrm{ng} / 50 \mu \mathrm{l}$ of fetuin for $4 \mathrm{~h}$ at room temperature, or overnight at $4{ }^{\circ} \mathrm{C}$. The coating solution was removed by aspiration and the wells were rinsed three times with $100 \mu \mathrm{l}$ of $1 / 15 \mathrm{M}$ phosphate buffered saline- $0.05 \%$ Tween 20 , pH 7.4 (PBS-Tween 20), then $100 \mu \mathrm{l}$ of PBS-Tween 20 containing $5 \%$ bovine serum albumin (BSA) was added for blocking. After being left for $1 \mathrm{~h}$ at room temperature, the blocking solution was aspirated and the wells were rinsed again three times with $100 \mu \mathrm{l}$ of PBS-Tween 20. The coated plates were stored for up to two weeks at $4{ }^{\circ} \mathrm{C}$ in a solution of PBS containing $0.03 \% \mathrm{NaN}_{3}$.

Assays of Sialidase Activity The enzymes used were from Vibrio cholerae, streptococcus, rat liver and the influenza A virus. The wells coated with fetuin were incubated for $1 \mathrm{~h}$ at $37^{\circ} \mathrm{C}$ after adding $50 \mu 1$ of $0.05 \mathrm{M}$ sodium acetate buffer adjusted to the optimum $\mathrm{pH}$ for each of the sialidases. The reaction was stopped with $100 \mu \mathrm{l}$ of $250 \mathrm{~mm}$ glycin- $\mathrm{NaOH}$ buffer, $\mathrm{pH} 10.4$. The reaction mixture was removed by aspiration and the wells were washed three times with $100 \mu$ l of PBS-Tween 20 . Next, $50 \mu \mathrm{l}$ of biotinylated $\mathrm{RCA}_{120}(50 \mu \mathrm{g} / \mathrm{ml})$ in PBS-Tween 20 was added to the wells. After standing for $1 \mathrm{~h}$ at room temperature, the wells were washed three times with $100 \mu 1$ of PBS-Tween 20 , and $100 \mu 1$ of the ABC kit (a solution mixture of avidin $\mathrm{DH}$ and biotinylated horseradish peroxidase $\mathrm{H}$ in PBS-Tween 20) was then added. After being left to stand for $1 \mathrm{~h}$ at room temperature, the wells were washed three times with $100 \mu$ l of PBS-Tween 20. Following this, $100 \mu \mathrm{l}$ of a chromogenic solution consisting of $12 \mathrm{mg}$ of solubilized $o$-phenylendiamine and $25 \mu$ l of $5 \% \mathrm{H}_{2} \mathrm{O}_{2}$ in $30 \mathrm{ml}$ of $0.1 \mathrm{M}$ citrate buffer, $\mathrm{pH} 4.5$, was added to the wells. The reaction was stopped with $50 \mu \mathrm{l}$ of $3 \mathrm{M} \mathrm{H}_{2} \mathrm{SO}_{4}$ and measured at $490 \mathrm{~nm}$ on the microplate reader. Fetuin and the enzyme added to the mixture solution were used as a background for the assay. Another assay using PNPN as a substrate was performed by incubating the solution, including the sialidase and substrate, for $1 \mathrm{~h}$ at $37^{\circ} \mathrm{C}$, followed by measurement at $415 \mathrm{~nm}$.

Inhibition of Lectin Binding to Asialo Fetuin by Some Sugars The microplate was coated with $30 \mathrm{ng} / 50 \mu \mathrm{l}$ of fetuin. Mixtures of $50 \mu \mathrm{l}$ of biotinylated $\mathrm{RCA}_{120}(50 \mu \mathrm{g} / \mathrm{ml})$ and individual sugars (1,10 and $100 \mathrm{mM}$ ) such as lactose, galactose, glucose, mannose, $\mathrm{N}$-acetyl-galactosamine and $\mathrm{N}$-acetyl-glucosamine, were incubated for $60 \mathrm{~min}$ at $37^{\circ} \mathrm{C}$ and placed in the asialo fetuin-coated well. The continuous methods were performed as described above. The percentage of inhibition was determined by the following formula:

$$
\begin{aligned}
& \text { inhibition }(\%)= \\
& \frac{\text { absorbance (without sugar) - absorbance (with sugar) }}{\text { absorbance (without sugar) }} \times 100
\end{aligned}
$$

Hemagglutination Assay (HA) of Influenza Virus ${ }^{13)}$ HA was titrated by combining $25 \mu \mathrm{l}$ of serial two-fold dilutions of the virus in PBS containing $0.01 \%$ gelatin with $25 \mu \mathrm{l}$ of $0.5 \%$ chicken erythrocytes. After incubation for $1 \mathrm{~h}$ at $4{ }^{\circ} \mathrm{C}$, the end point was estimated visually, and the reciprocal of the end point dilution was defined as the titer.

Analytical and Chemical Analysis The protein content was determined using the Bio-Rad Protein Assay procedure based on dye-binding assay on the 96-well microplate. ${ }^{14)}$ The sialic acid content was determined by colorimetric assay as previously described. ${ }^{15)}$

\section{RESULTS AND DISCUSSION}

The small scale multiscreening solid phase method for the sialidase activity is schematically outlined in Fig. 1. The fetuin had trisialyl triantennary sugar chains $(74 \%)^{16}$ ) and was a good substrate for this assay system, compared to transferin and the $\alpha 1$-acid glycoprotein-bearing exposed galactose residue, resulting in low background levels. In
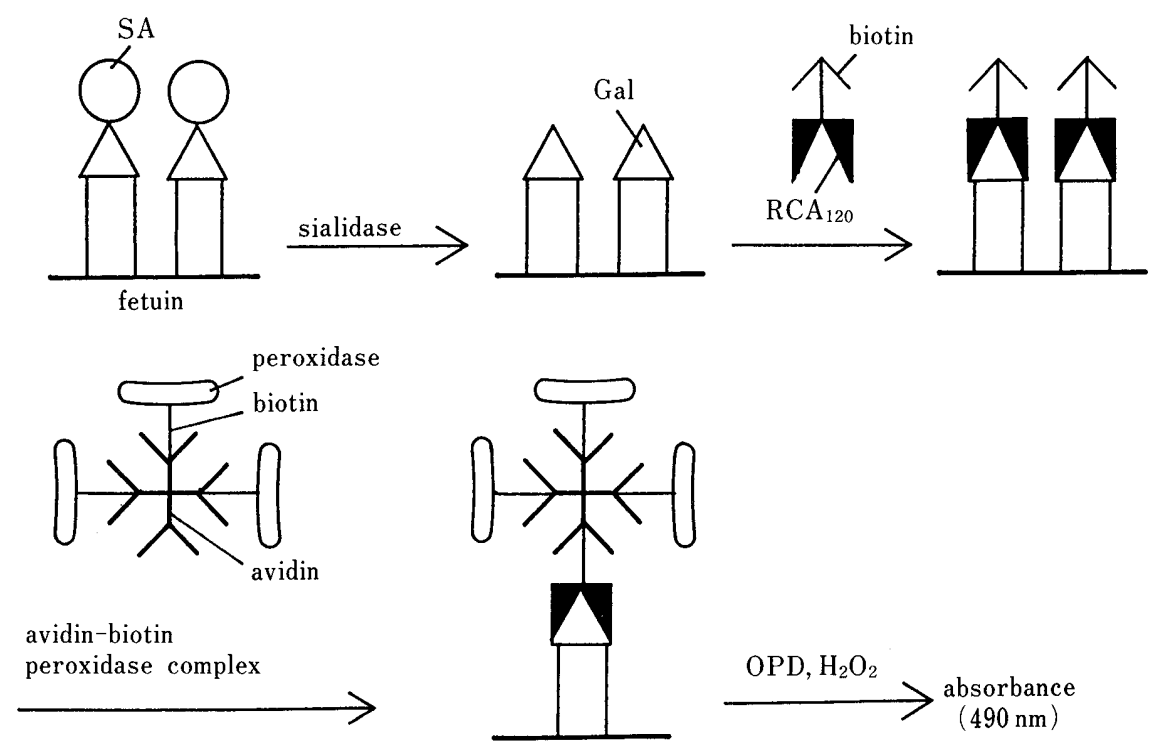

Fig. 1. Schematic Representation of Sialidase Assay in a Solid Phase Using Fetuin

$\mathrm{SA}$, sialic acid; Gal, galactose; $\mathrm{RCA}_{120}$, Ricinus communis agglutinin 120; $\mathrm{OPD}$ o-phenylendiamine. 


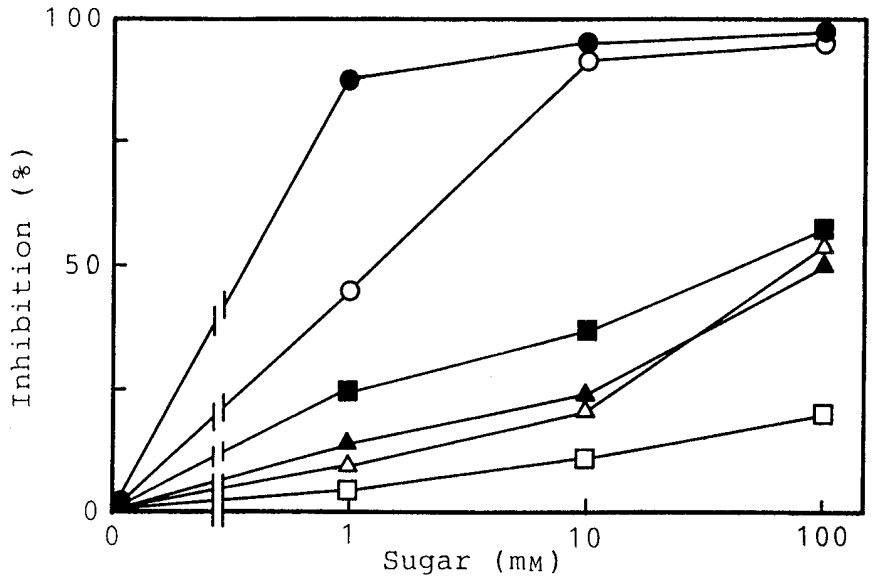

Fig. 2. Inhibition of Lectin Binding to Asialo Fetuin by Some Sugars A preincubated suspension of lectin and each of the sugars was added to asialo fetuin-coated wells. The continuous procedure was performed as described in Materials and Methods. - - , lactose; - $\mathrm{O}-$, galactose; - $-\mathrm{D}$-acetylgalactosamine; $-\triangle-$, glucose; $-\mathbf{\Delta}-$, mannose; $-\square-, N$-acetyl-glucosamine.

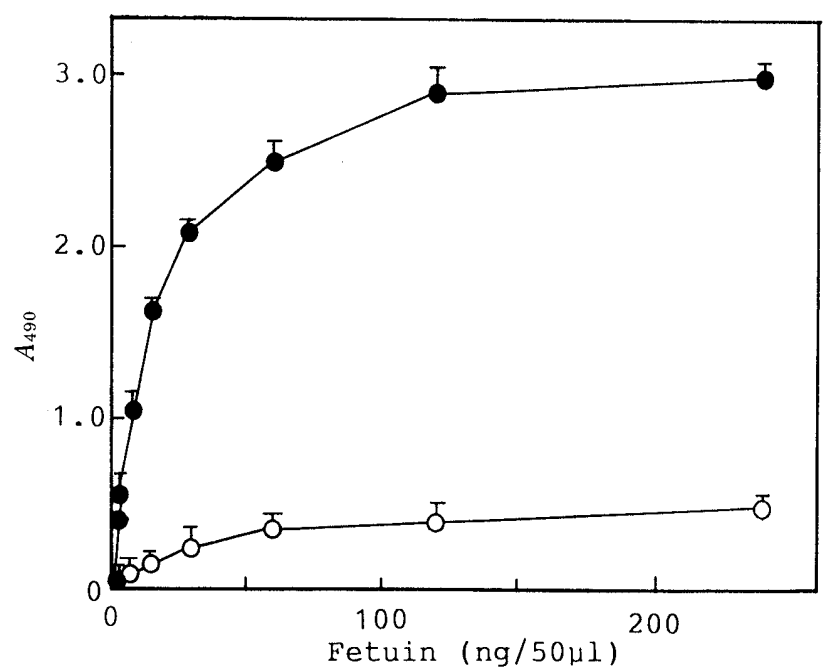

Fig. 3. Sialidase Activity Using Sialidase from Vibrio cholerae in Various Concentrations of Fetuin

The assay was done with $(\mathbf{O})$ and without $(O)$ sialidase. The absorbance at $490 \mathrm{~nm}$ was monitored. The results represent the means \pm S.D. of triplicate determinations. this assay, the key point for the high sensitivity is the utilization of the avidin-biotin peroxidase complex. It was reported that the lectin, $\mathrm{RCA}_{120}$, bound with a high affinity to the structure of the Gal $\beta$ 1-4 GlcNAc disaccharides, but significantly reduced the association with sialylated $\mathrm{Gal} \beta$ 1-4 GlcNAc. ${ }^{17)}$ As shown in Fig. 2, the binding of $\mathrm{RCA}_{120}$ to $\mathrm{Gal} \beta$ 1-4 GlcNAc disaccharides was inhibited by mono- or disaccharides; especially, by lactose, rather than galactose, which displayed strong inhibition. Inhibition assay using other sugars was low. However, inhibition for increasing sugars $(100 \mathrm{~mm})$ may be caused by steric hindrance. In addition, when asialofetuin was treated with $\beta$-galactosidase, the binding to $\mathrm{RCA}_{120}$ significantly decreased (data not shown). These results are consistent with the specificity of $\mathrm{RCA}_{120}$ described previously. ${ }^{17)}$

Figure 3 shows sialidase activity in various concentrations of fetuin to determine the optimum concentration

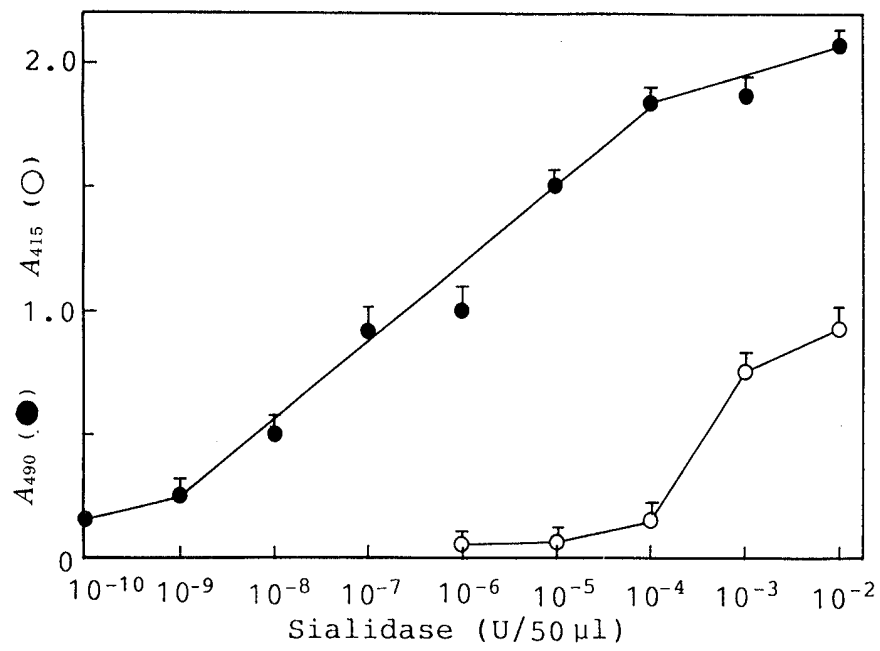

Fig. 4. Sialidase Activity in Various Dilutions of Sialidase from Vibrio cholerae Using Either Fetuin (O) PNPN (O) as a Substrate

Microplates were coated with $30 \mathrm{ng} / 50 \mu \mathrm{l}$ of fetuin. Sialidase was diluted in $10^{-2}-10^{-10} \mathrm{U} / 50 \mu \mathrm{l}$ with $0.1 \mathrm{M}$ sodium acetate buffer, $\mathrm{pH} 6.5$. The absorbances at $490 \mathrm{~nm}$ for fetuin and at $415 \mathrm{~nm}$ for PNPN were monitored. The results represent the means \pm S.D. of triplicate determinations.
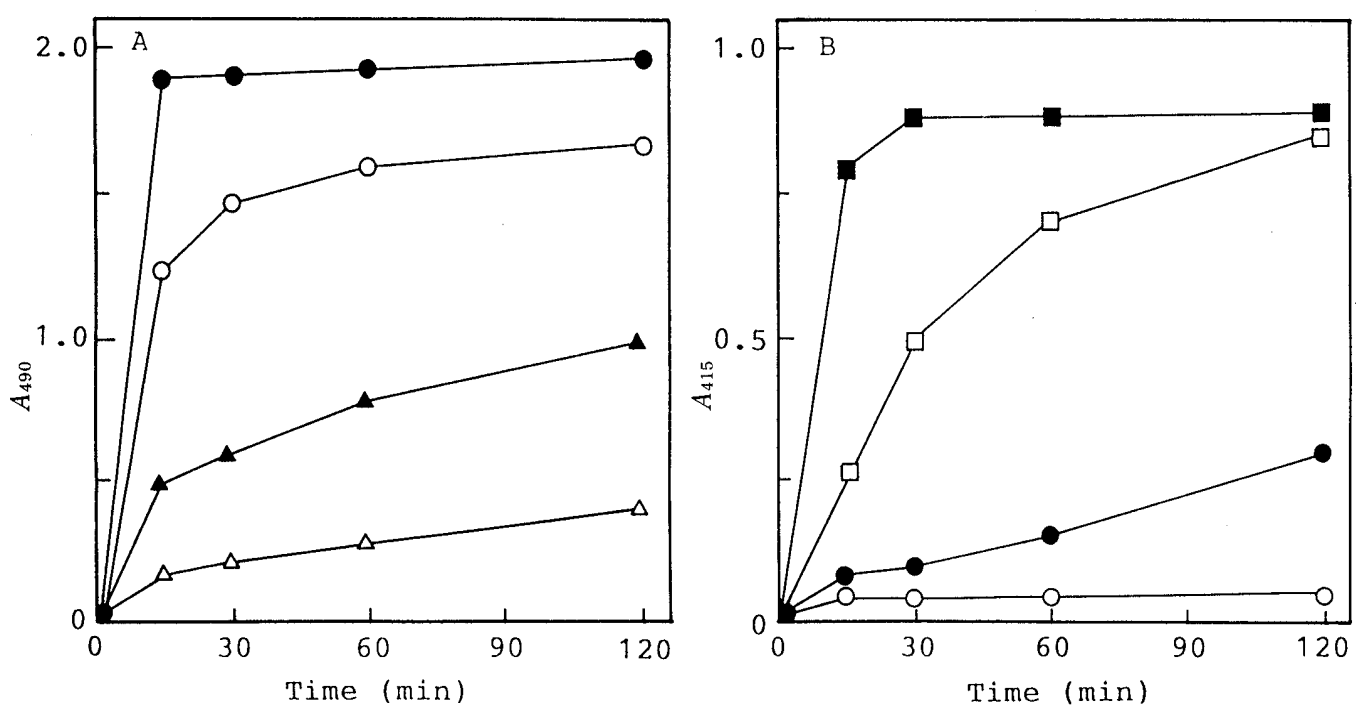

Fig. 5. The Time Course in Various Dilutions of Sialidase from Vibrio cholerae Using Fetuin (A) or PNPN (B) as Substrates

Microplates were coated with $30 \mathrm{ng} / 50 \mu \mathrm{l}$ of fetuin. Sialidase for PNPN was diluted in $10^{-2}-10^{-5} \mathrm{U} / 50 \mu \mathrm{l}$ with a $0.1 \mathrm{M}$ sodium acetate buffer, $\mathrm{pH} 6.5$, and sialidase for fetuin was diluted in $10^{-4}-10^{-8} \mathrm{U} / 50 \mu \mathrm{l}$ with the same buffer. $-0-10^{-4} \mathrm{U} / 50 \mu \mathrm{l} ;-\mathrm{O}-, 10^{-5} \mathrm{U} / 50 \mu \mathrm{l} ;-\mathbf{\Delta}-, 10^{-6} \mathrm{U} / 50 \mu \mathrm{l} ;-\triangle-, 10^{-8} \mathrm{U} / 50 \mu \mathrm{l} ;-\square-$ $10^{-2} \mathrm{U} / 50 \mu \mathrm{l} ;-\square-, 10^{-3} \mathrm{U} / 50 \mu \mathrm{l}$. The reaction time was $0-120 \mathrm{~min}$. The absorbances at $490 \mathrm{~nm}$ for fetuin and at $415 \mathrm{~nm}$ for PNPN were monitored. 

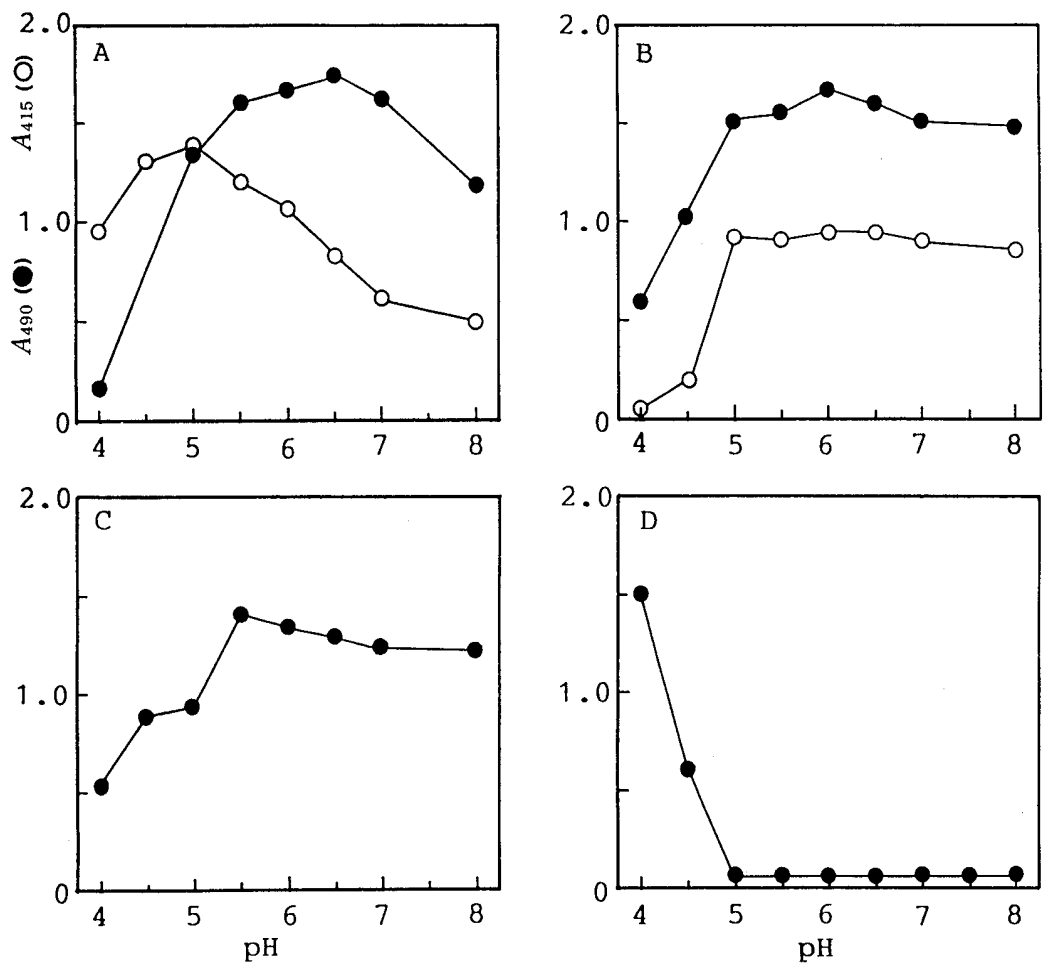

Fig. 6. The pH Range of Four Different Sialidases Using Fetuin (O) or PNPN (O) as a Substrate

The sialidase was from Vibrio cholerae (A), streptococcus (B), influenza A virus particle (C), and the homogenized supernatant of the lysozomal fraction from rat liver (D). The $\mathrm{pH}$ range was adjusted to $4-8$ with $0.1 \mathrm{~m}$ sodium acetate buffer. The absorbances at $490 \mathrm{~nm}$ for fetuin and at $415 \mathrm{~nm}$ for PNPN were monitored.

of fetuin. The reaction reached a plateau at the concentration of $100 \mathrm{ng} / 50 \mu \mathrm{l}$ of fetuin. The background levels (no sialidase) were relatively low, indicating that the fetuin had very little exposed galactose residue to react with $\mathrm{RCA}_{120}$. This is the reason fetuin was used as a substrate.

The dilution of sialidase was compared as to the sensitivity of the enzymatic assay using the avidin-biotinperoxidase complex with that of the colorimetric assay using PNPN as a substrate. As shown in Fig. 4, the reaction was linear, ranging from $10^{-4}$ to $10^{-9} \mathrm{U} / 50 \mu \mathrm{l}$; therefore, the sensitivity obtained by utilizing fetuin $(30 \mathrm{ng} / 50 \mu \mathrm{l})$ was 1000 - to 10000 -fold higher in comparison with the colorimetric assay. Additional results were obvious in the time course of the diluted sialidase (Fig. 5). The reaction mixture using PNPN as a substrate was incubated for $120 \mathrm{~min}$ but had a very low activity in $10^{-4}$ or $10^{-5} / 50 \mu \mathrm{l}$ of the diluted sialidase. However, the reaction using fetuin reached a plateau after $15 \mathrm{~min}$ under the condition of $10^{-4} \mathrm{U} / 50 \mu \mathrm{l}$, as above. These results indicate that the assay developed in this paper has a much higher sensitivity than the colorimetric assay. Furthermore, low activity such as $10^{-6}$ or $10^{-8} \mathrm{U} / 50 \mu \mathrm{l}$ can be monitored by employing a long incubation time. For example, it may be possible to measure low sialidase activity in body fluids, cells and tissues. The above results were the same in terms of sensitivity as the method using a synthetic fluorescent substrate ${ }^{6)}$ or the radiolabelled substrate. ${ }^{7)}$ Furthermore, this assay system was ascertained to have high reproducibility according to the levels of standard deviation shown in Figs. 3 and 4. The diluted sialidase was stable for at least two weeks at $4{ }^{\circ} \mathrm{C}$ in the presence of $0.1 \%$ BSA.

Figure 6 shows the $\mathrm{pH}$ range of the four types of

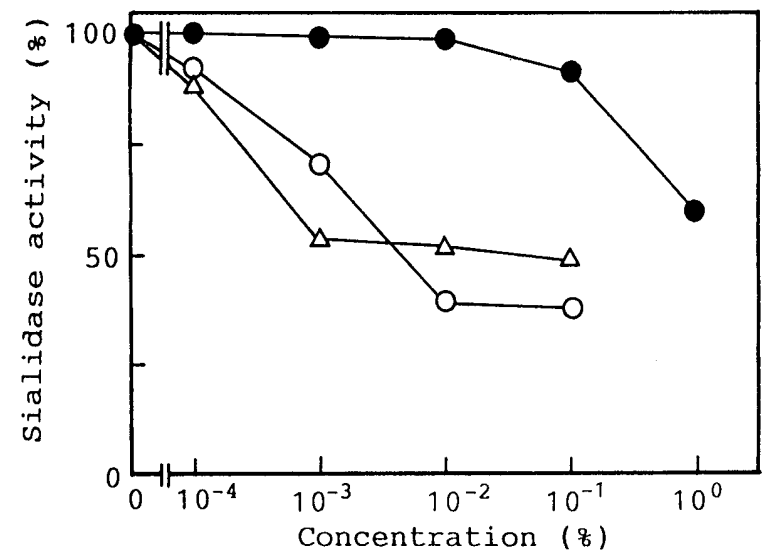

Fig. 7. The Effects of Three Detergents on Sialidase Activity

Sialidase from Vibrio cholerae was used at $10^{-4} \mathrm{U} / 50 \mu$. Detergents used were taurodeoxycholic acid $(\circlearrowleft)$, Tween $20(\triangle)$ and Triton X-100 $(O)$. The absorbance at $490 \mathrm{~nm}$ was monitored.

sialidases. Except for the sialidase derived from rat liver, sialidase activity was effective at $\mathrm{pH} 5-7$. The optimal $\mathrm{pH}$ of lysosomal sialidase from rat liver was 4 . A system using a microplate is most useful in cases which investigate the $\mathrm{pH}$ range at once by adding an adjusted $\mathrm{pH}$ buffer to the wells coated with fetuin. The selection of a detergent is very important in the extraction of sialidase from tissues and cells without incurring a significant loss of activity. Figure 7 shows the effects of detergents that were used on the sialidase activity. The sialidase activity was inhibited by more than $50 \%$ using $0.01 \%$ Tween 20 and Triton $\mathrm{X}-100$; whereas, in the case of $0.1 \%$ taurodeoxycholic acid, sialidase activity was maintained at more than $90 \%$. Therefore, it appears that taurodeoxycholic acid is appropriate for extracting sialidase from tissues while 


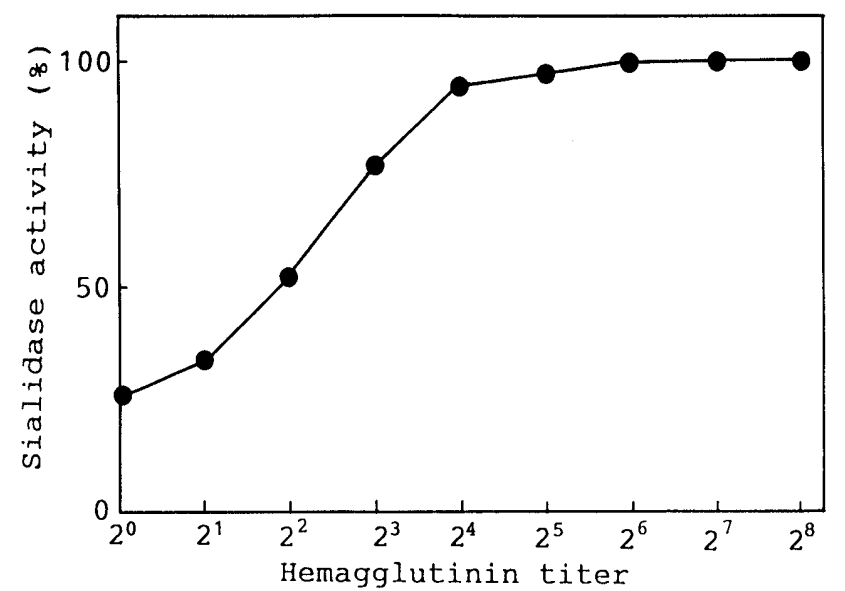

Fig. 8. The Relationship between Sialidase Activity and the Hemagglutinin Titer of the Influenza Virus (A/Aichi/2/68, H3N3)

The plates were coated with $50 \mathrm{ng} / 50 \mu \mathrm{l}$ of fetuin. Serial two-fold dilutions of the influenza $\mathrm{A}$ virus were combined with $0.1 \mathrm{~m}$ sodium acetate buffer, $\mathrm{pH}$ 5.5. The sialidase activity and hemagglutinin titer were determined as described in Materials and Methods.

maintaining its activity.

Figure 8 shows the relationship between sialidase activity and the hemagglutinin titer of the influenza $\mathrm{A}$ virus. The culture of the influenza virus required more time and cost; hence, Fig. 8 indicates that the assay system described in this paper is useful to measure the sialidase activity of only a small amount of the influenza virus for the preparation of sialidase.

This method is currently used in our laboratories, both for monitoring column fractions for sialidase activity in the course of purification of the enzyme, and in screening clinical body fluid samples for alterations in sialidase activity. Sialidase activity can be specifically detected by this assay in crude biological samples, and the procedure of this assay is simpler and safer with higher reproducibility than that of conventional radiochemical methods.

\section{REFERENCES}

1) R. Schauer, Trends Biochem. Sci., 9, 357 (1985).

2) U. Rutishauser, A. Acheson, A. K. Hall, D. M. Mann, J. Sunshine, Science, 240, 53 (1988).

3) L. Aarren, J. Biol. Chem., 234, 1971 (1959).

4) D. Aminoff, Biochem. J., 81, 384 (1961).

5) P. Palese, D. Bucher, E. D. Kilbourne, Appl. Microbiol., 25, 195 (1973).

6) M. Potier, L. Mameli, M. Bilisle, L. Dallaire, S. B. Melancon, Anal. Biochem., 94, 287 (1979).

7) V. P. Bhavanandan, A. K. Yen, R. Carubelli, Anal. Biochem., 69, 385 (1975).

8) R. Alon, E. A. Bayer, M. Wilcheh, J. Biochem. Biophy. Methods, 22, 23 (1991).

9) K. Ogura, M. Ogura, R. L. Anderson, C. C. Sweely, Anal. Biochem., 200, 52 (1992).

10) T. Nagai, H. Yamada, Chem. Pharm. Bull., 37, 2243 (1989).

11) C. R. Lambre, H. Terzidis, A. Greffard, R. G. Wesbster, Clin. Chim. Acta, 198, 183 (1991).

12) T. Miyagi, S. Tsuiki, Eur. J. Biochem., 141, 75 (1984).

13) J. K. Collins, C. A. Knight, J. Virol., 27, 164 (1978).

14) M. Bradford, Anal. Biochem., 72, 248 (1976).

15) K. Sugahara, Clin. Chim. Acta, 108, 493 (1980).

16) S. Takasaki, A. Kobata, Biochemistry, 25, 5709 (1986).

17) J. U. Baenziger, D. Fiete, J. Biol. Chem., 254, 9795 (1979). 